\title{
N-15 and C-13 CPMAS and solution NMR studies of N-15 enriched plant material during 600 days of microbial degradation
}

\author{
H. KNICKER* and H.-D. LÜDEMANN
}

\begin{abstract}
Summary - Nitrogen-15 enriched plants (Lolium perenne (rye grass) and Triticum satitum (wheat)) have been composted under controlled conditions up to 630 days. The composts were characterized by $\mathrm{C}-13$ and $\mathrm{N}-15$ CPMAS spectra. For some composts $\mathrm{N}-15 \mathrm{HR}$ NMR solution spectra of the $\mathrm{NaOH}$ extracts were studied. The composts were characterized by weight loss and elementary analysis. Most of the nitrogen detectable is assigned to amide/peptide structures $(80-90 \%)$, the remaining intensities being found in the chemical shift region of amino- and ammonium groups. Signals for nitrogen-containing heterocycles were not observed. Less than $5 \%$ of the intensity on the low field side of the main peptide/amide signal might be ascribed to indole/imidazole/uric acid derivatives. Combined analysis of C-13 CPMAS spectra, the elemental analysis and mass balance, yield the result that all chemical structures visible in the $\mathrm{C}-13$ spectra are altered in the composting process, although at different rates.
\end{abstract}

Key words-N-15 NMR, C-13 NMR, composts, humic substances, soil organic matter, nitrogen in humics

\section{INTRODUCTION}

Soil organic matter (SOM) and associated sediments comprise the major repository for organic carbon and nitrogen on the Earth's surface (Aiken et al., 1985; Stevenson and Kelley, 1985). Besides being the most abundant and ubiquitous natural organic product in the biosphere SOM can also be the precursor for some fossil fuels, especially if buried anaerobically as peat. The starting material for SOM is composed of a mixture of dead plant material (primary resources) and animal and microbial residues (secondary resources). During the humification and mineralization process, the starting plant material which consists mainly of insoluble lignocellulosics, is thoroughly converted by microorganisms. Concomitantly with the microbial decomposition, stabilization of the degradation products occurs leading to the formation of refractory SOM, which resists further chemical modification for hundreds to several thousands of years (Hsieh, 1992). During these long periods new nitrogen-containing structures can be formed that are not seen in the early transformation stages. This process may include the formation of aromatic heterocycles (Flaig et al., 1975; Stevenson and Kelley, 1985; Anderson et al., 1989). The emphasis of this study is the characterization of the forms of nitrogen in soil. The long term composting of isotopically $\mathrm{N}$-15-enriched plant material is applied to simulate natural plant degradation and soil formation. The products of this process are characterized by nuclear magnetic resonance (NMR).

Application of the cross polarization magic angle spinning (CPMAS) technique (Fyfe, 1983; Wilson, 1987 ) is unique among the many physical analytical methods applied to elucidate the structure of the various fractions of SOM, since it permits the study of complete soils without any prior chemical treatment. Careful optimization of the instrument parameters with respect to sensitivity is necessary for the study of soils, containing around $1 \%$ of total organic carbon, in acceptable instrument times. Remember, however, that a solid state spectrum of an amorphous, complex, blend of polymers can never completely match the resolution obtainable in a solution high resolution NMR spectrum. The assignments possible are thus confined to classes of carbon atoms. Furthermore, the overlap in chemical shifts between, for instance, carbohydrate structures and the $\mathrm{C}$-carbons of proteinaceous material renders some of the assignments ambiguous. For the spectra of the composts given in the text, the specific assignments also rely on the changes observed when the chemically welldefined starting plant material is compared to the compost samples taken after various lengths of composting time.

C-13 CPMAS analysis of humic material is a well established technique. However, the element of greatest importance to the agricultural value of SOM is nitrogen. NMR studies of this element are hampered by two physical facts: the most abundant nitrogen 
isotope $\mathrm{N}-14$, has a large quadrupole moment and thus it is impossible to obtain high resolution spectra from this nucleus (Witanowski et al., 1986). The dipolar nucleus $\mathrm{N}-15$ on the other hand combines a low natural abundance of $0.37 \%$ with a low gyromagnetic ratio and thus the sensitivity of an N-15 NMR experiment, of a sample without isotopic enrichment, is approximately a factor of 50 lower than for a $\mathrm{C}-13$ spectrum. This may be the reason that in soil science and geoscience N-15 NMR has been applied in only a few studies (Benzing-Purdie et al., 1983, 1986, 1992; Cheshire et al., 1990). To overcome this low sensitivity, the composts studied here were prepared from plants grown on N-15 enriched fertilizers. Two main problems were addressed: the characterization of the chemical structures of the nitrogen-containing moieties formed during composting, and the study of all relevant NMR relaxation times of the nitrogen, in the solid-state and in solution, in order to optimize the sensitivity of the measurement and to avoid intensitydisturbing magnetic saturation effects.

\section{MATERIAL AND METHODS}

\section{Sample preparation}

Young stems of Lolium perenne, from pot experiments, collected at intervals of 14 days (approx. $90 \%$ enriched in $\mathrm{N}-15$ ) and green winter wheat collected at ear-emergence from field experiments with N-15 labeled fertilizer (Triticum sativum: approx. 16\% enriched in $\mathrm{N}-15$ ), were freeze dried and milled to a fine powder. This material was mixed in a ratio 100:6 with fine quartz sand $(0.3-0.4 \mathrm{~mm})$. Depending on the composting time, $100-250 \mathrm{~g}$ of this mixture, in glass beakers, was inoculated with an aqueous extract obtained from a natural compost. For each of the plant residues, a series was started at $60 \%$ water holding capacity (WHC) and at water saturation $(100 \%$ WHC). The samples, in a closed desiccator, were aerated by a slow stream of moistened $\mathrm{CO}_{2}$-free air. Carbon loss from the material was determined by absorbing the carbon dioxide in aqueous $0.5 \mathrm{~N}$ sodium hydroxide solution, followed by titration of the residual $\mathrm{NaOH}$ after precipitation of the carbonate with barium chloride. The weight loss of the samples was determined from smaller samples after thoroughly drying the complete containers over phosphorous pentoxide. After measured periods of composting time, the residual organic material was mechanically separated from the quartz sand which was washed several times with triply distilled water, to separate the residual organic fraction. This wash was combined with the mechanically separated solid parts and then lyophilized. Spectra of the complete dried mixture were frequently compared with those of the residue of the vacuum evaporation, until no significant differences between the two samples were apparent. The separation of the organic phase from the sand was necessary to increase the concentration of carbon and nitrogen in the samples, thus saving spectrometer time.

Some of the samples were extracted with aqueous $0.5 \mathrm{~N} \mathrm{NaOH}$ in order to separate the three fractions: humin (residue of extraction), humic acid (acid insoluble part of the $\mathrm{NaOH}$ extract) and fulvic acid (matter soluble in aqueous $\mathrm{HCl}$ at $\mathrm{pH}=1$ ). The complete $\mathrm{NaOH}$-extract was also studied in some cases. Details of the extraction process are given in Fründ and Lüdemann (1991). The C,H,N contents of the composts were determined by standard elemental analysis at the microanalysis laboratory, of the University of Regensburg. The $\mathrm{pH}$ value were measured in a $1: 10$ suspension of the composting mixture in triply distilled water.

\section{NMR-methods}

The C-13 CPMAS spectra were obtained on a Bruker MSL-100 spectrometer at a frequency of 25.2 $\mathrm{MHz}$ with magic angle spinning at $4 \mathrm{kHz}$. A commercial double bearing probe of $7 \mathrm{~mm}$ o.d., and a phase stabilized zirconium dioxide rotor were used. The C-13-chemical shifts were calibrated against tetramethylsilane. Details of the experimental procedure have been given previously (Fründ and Lüdemann, 1989a, b, 1991). A single HartmannHahn contact time of $1 \mathrm{~ms}$ was used. For the starting material a repetition time of $5 \mathrm{~s}$ was applied while for the composted material a repetition time of $300 \mathrm{~ms}$ was sufficient. For the C-13 CPMAS spectra 20,000 scans were accumulated.

The N-15 HR NMR-solution and N-15 CPMAS solid state spectra were obtained on a Bruker MSL-300 spectrometer at a frequency of $30.4 \mathrm{MHz}$. For the solution spectra a commercial $10 \mathrm{~mm}$ variable frequency probe head was used. The CPMAS spectra were obtained in a probe head of similar design as used for the C-13 studies. The chemical shifts are given relative to nitromethane. For the solution $\mathrm{N}-15$ spectra the standard pulse program used was the Ridegate-sequence (Gerothanassis, 1986; Fründ, 1988), which effectively suppresses the acoustic ringing. The protons were decoupled by the inverse gated broadband decoupling scheme in order to suppress the nuclear Overhauser enhancement that could introduce intensity distortions. In order to avoid saturation effects in the spectra, $T_{\mathrm{IN}-15}$ were determined by the normal inversion recovery pulse sequence. For the N-15 CPMAS spectra all relevant magnetization transfer- and relaxation rates were determined by standard procedures (Wilson, 1987). The polarization transfer time, $T_{\mathrm{NH}}$, and the proton spin lattice relaxation time in the rotating frame, $T_{\mathrm{IH}}$, were determined from a series of spectra as a function of the Hartmann-Hahn-contact time, $t$. The proton spin lattice relaxation, $T_{\mathrm{IH}}$. was determined indirectly in the $\mathrm{N}$-15-CPMAS spectra by a special pulse sequence (Dev et al., 1987). A more detailed discussion of the relevant relaxation times, and their influence upon the 


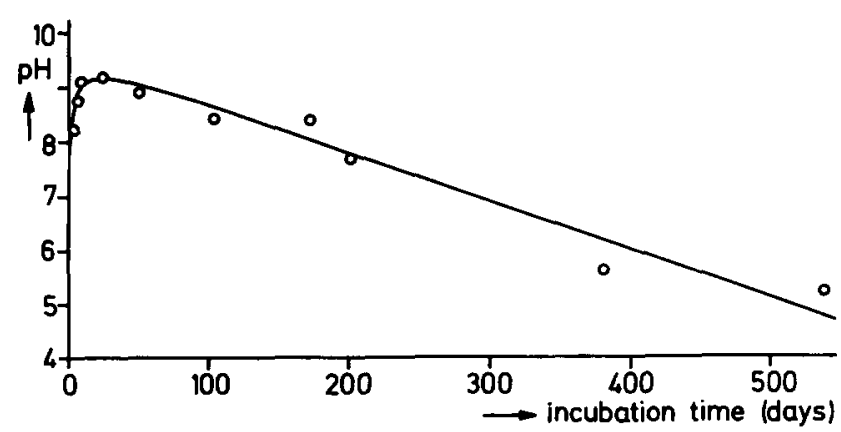

Fig. 1. $\mathrm{pH}\left(\mathrm{H}_{2} \mathrm{O}\right)$ of a N-15 enriched $L$. perenne compost at $60 \%$ WHC as a function of composting time.

The line drawn through the experimental points is a guide to the eye only.

relative intensities, is given by Knicker et al. (1995) and Knicker (1993).

\section{RESULTS AND DISCUSSION}

\section{Chemical analysis}

Figure 1 gives the $\mathrm{pH}$-values for the $L$. perenne compost at $60 \%$ WHC. This curve is representative for all four series studied. A slight initial increase in $\mathrm{pH}$ is followed by a slowly decreasing $\mathrm{pH}$ during further composting. This is caused by nitrification of ammonia and by the formation of carboxylic acids and bicarbonate ions in the decomposing plant material. (The $\mathrm{C}-13$ spectra discussed below show a strong increase in the carbonyl/carboxyl range during composting.) In Fig. 2 the weight and carbon loss of the composts is given as a function of composting time. The results are in general agreement with reports recently published (Foster et al., 1993). The process can be subdivided into
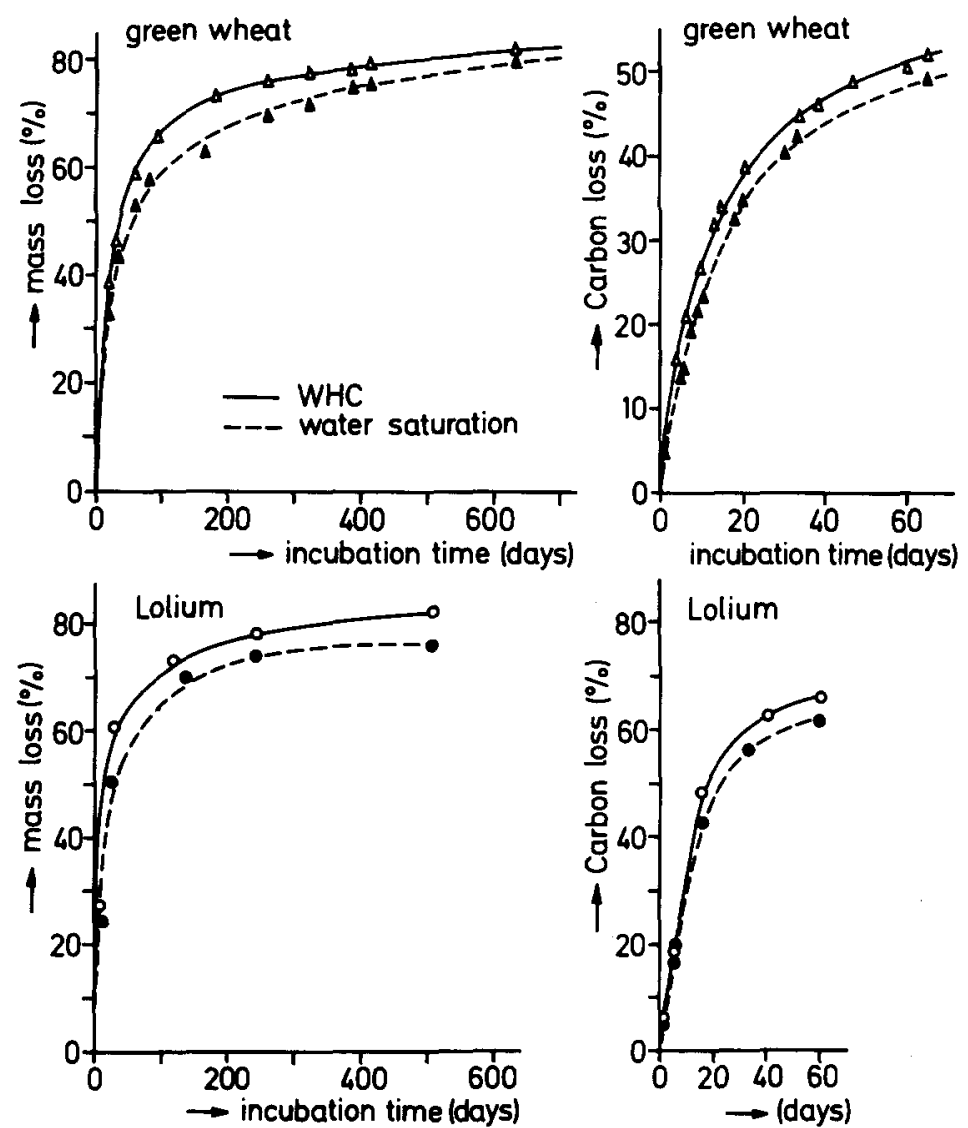

Fig. 2. Weight- and carbon loss of the composts from $L$. perenne and green wheat stems as function a of composting time at $25^{\circ} \mathrm{C}$. 


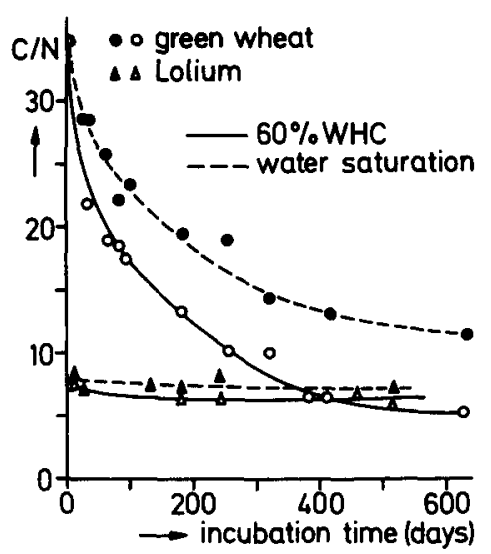

Fig. 3. Variation of the $\mathrm{C} / \mathrm{N}$ ratio of the four composting series during fermentation.

three consecutive periods with decreasing decomposition rates (Kirchmann and Bergqvist, 1989; Haider, 1992). However, these data alone do not yield any information about the differences in decomposition rates observed for the various fractions of the plant material. At the end of our composting experiments, the starting materials had lost more than $80 \%$ of their mass. An indication of the changed chemical composition of the composts is given by the $\mathrm{C} / \mathrm{N}$ ratio of the organic residues as compiled in Fig. 3. The $\mathrm{C} / \mathrm{N}$ ratio of the $L$. perenne starting material is unusually low, since only very young plant material was used. For the green wheat samples at $60 \% \mathrm{WHC}$ these data correspond to a nitrogen loss of $30 \%$. In the $60 \%$ WHC $L$. perenne composting experiment, $80 \%$ of the total nitrogen is lost from the sample, whereas from the water-saturated sample approx. $90 \%$ has been removed.
Table $1 . \mathrm{T}_{15}$ is (s) at $30.4 \mathrm{MHz}$ for one unspecified fungus grown on the compost, the $\mathrm{NaOH}$ extract of the starting material, and the $\mathrm{NaOH}$-extracts collected after various composting periods

\begin{tabular}{ccccccc}
\hline Signal (ppm) & -257 & -269 & -294 & -306 & -346 & -358 \\
\hline 15N-Lolium: & & & & & & \\
0 days & $0.9 \mathrm{~s}$ & $0.5 \mathrm{~s}$ & $0.9 \mathrm{~s}$ & $0.9 \mathrm{~s}$ & $1.1 \mathrm{~s}$ & \\
7 days & $0.6 \mathrm{~s}$ & $0.4 \mathrm{~s}$ & $0.6 \mathrm{~s}$ & $0.7 \mathrm{~s}$ & $1.2 \mathrm{~s}$ & $3.0 \mathrm{~s}$ \\
174 days & $0.5 \mathrm{~s}$ & $0.7 \mathrm{~s}$ & $0.6 \mathrm{~s}$ & $0.7 \mathrm{~s}$ & - & - \\
541 days & $0.6 \mathrm{~s}$ & $0.6 \mathrm{~s}$ & - & - & $0.4 \mathrm{~s}$ & $0.6 \mathrm{~s}$ \\
\hline
\end{tabular}

\section{Systematic studies for the optimization of the NMR} experiments

The sensitivity of the NMR experiments can only be optimized when all relevant relaxation parameters are known. For the $\mathrm{C}-13$ nucleus this has been done in several previous studies (Fründ and Lüdemann, 1989b; Fründ, 1988; Preston et al., 1994). These studies demonstrate that the relaxation behavior of humic materials is fairly uniform, therefore a set of standard experimental parameters can be derived that permits a quantitative integration of the spectra. The relaxation behavior for all the relevant nuclei in this study were determined from signal intensity data using commercially available software for the Bruker instruments. The results for $T_{1 \mathrm{H}}$ are presented in Fig. 4. Tables 1-4 contain representative results for all relevant relaxation times as a function of the relative spectral regions. For the N-15 nucleus, most of this information was previously unavailable in the literature. The composts examined in this study, as well as most humic materials, cannot perhaps, be described by a single correlation time, and are more appropriately characterized by a distribution of correlation times. They do, however, permit the recording of quantitative spectra within the precision possible in our experiments. In solution N-15 NMR studies, with inverse gated decoupling only, the $T_{\mathrm{IN}-1 \mathrm{~s}}$

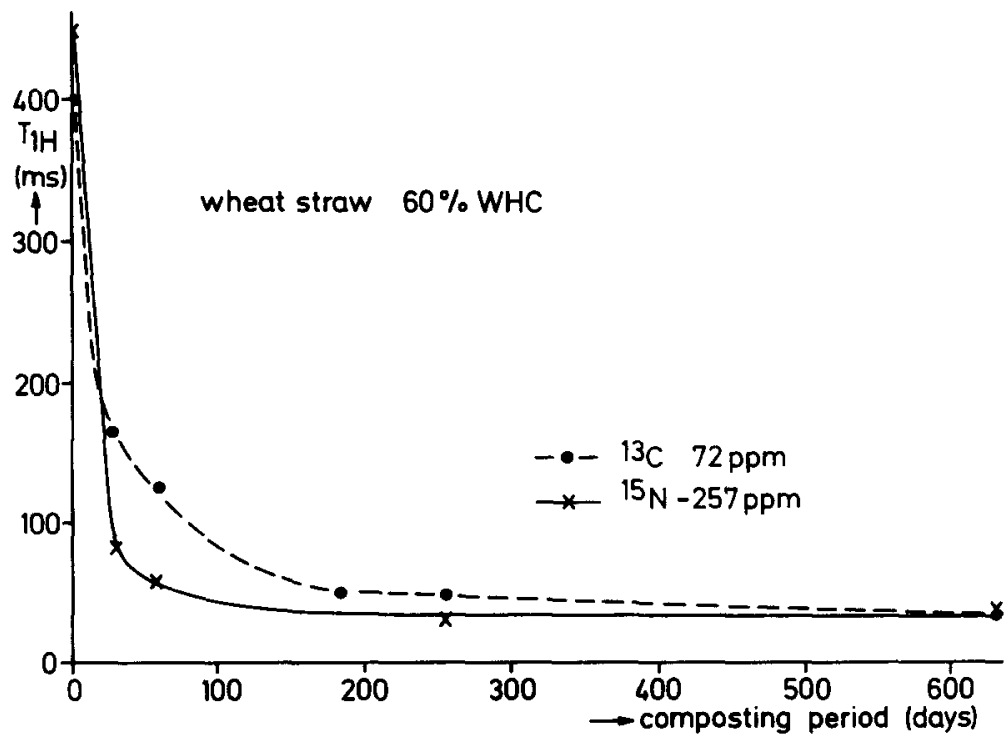

Fig. 4. $T_{1 \mathrm{H}}$ at $293 \mathrm{~K}$ as a function of the composting period. Derived for $\mathrm{C}-13$ from the peak at 72 ppm and for N-15 from the peak at $-257 \mathrm{ppm}$ in the spectra of a complete wheat compost $(60 \% \mathrm{WHC})$. 
Table 2. The longest proton spin lattice relaxation times observed in the solid state $\mathrm{N}-15$ and C-13 CPMAS spectra of the solid $\mathrm{NaOH}$ extracts and the insoluble residues

\begin{tabular}{|c|c|c|c|c|c|c|c|c|}
\hline & \multicolumn{2}{|c|}{0 days } & \multicolumn{2}{|c|}{174 days } & \multicolumn{2}{|c|}{248 days } & \multicolumn{2}{|c|}{174 days } \\
\hline & $\begin{array}{l}\mathrm{NaOH} \\
\text { extract }\end{array}$ & Residue & $\begin{array}{l}\mathrm{NaOH} \\
\text { extract }\end{array}$ & Residue & $\begin{array}{l}\mathrm{NaOH} \\
\text { extract }\end{array}$ & Residue & Humic acid & Fulvic acid \\
\hline${ }^{13} \mathrm{C}$ & $40 \mathrm{~ms}$ & $50 \mathrm{~ms}$ & $30 \mathrm{~ms}$ & $60 \mathrm{~ms}$ & $30 \mathrm{~ms}$ & $50 \mathrm{~ms}$ & $40 \mathrm{~ms}$ & $30 \mathrm{~ms}$ \\
\hline${ }^{15} \mathrm{~N}$ & - & - & $40 \mathrm{~ms}$ & $50 \mathrm{~ms}$ & $40 \mathrm{~ms}$ & $70 \mathrm{~ms}$ & $70 \mathrm{~ms}$ & $20 \mathrm{~ms}$ \\
\hline
\end{tabular}

has to be considered. Magnetic saturation effects will not be observed if the time between two RF pulses is larger than $5 T_{1 \mathrm{~N}-15}$. These data are compiled in Table 1. They are very similar to results obtained for other macromolecules in aqueous solution at room temperature (Martin et al., 1981; Clore et al., 1990). Based upon this analysis, standard experiments can thus be performed with a pulse delay of $6 \mathrm{~s}$.

To avoid saturation effects in CPMAS N-15 and C-13 spectra, the proton spin lattice relaxation time $T_{1 \mathrm{H}}$ of the protons interacting with the nucleus under study is relevant. For one signal each in the CPMAS $\mathrm{N}-15$ and C-13 spectra of composted wheat, Fig. 4 displays $T_{\mathrm{IH}}$ as a function of the composting period. In Table 2, the longest $T_{1 \mathrm{H}}$ for the two nuclei are compiled. A more complete set of $T_{1 \mathrm{H}^{-}}$-data is given in (Knicker, 1993). For a series of samples the intensity of the individual peaks in the N-15 CPMAS spectra was studied as a function of the Hartmann-Hahn-contact time. In all cases the intensity showed a very sharp increase for short contact times $(t>0.3 \mathrm{~ms})$, passed through a maximum around $t=0.5 \mathrm{~ms}$, and showed a slow decrease for $t<1.0$. This variation of the intensity, $I$, as function of the contact time, $t$, shows that the inequality $T_{\mathrm{NH}} \ll T_{1 \mathrm{H}}$ is valid for all materials studied here.

In Tables 3 and 4, representative examples of $T_{\mathrm{NH}}$ and $T_{1 \mathrm{H}}$ are collected for a small series of the $\mathrm{N}-15$ signals. With this data, it becomes straightforward to choose a set of optimal experimental parameters for the efficient collection of spectra that will permit analysis of the composting process.

\section{Chemical assignments}

For the quantitative analysis of NMR spectra, it is customary to subdivide them into chemical shift ranges and to obtain the relative concentrations of the different chemical structures from this integral. The C-13 spectra, especially, exhibit broadly distributed intensities over the whole range of chemical shifts, and thus the subdivision is not without ambiguity. For instance, the chemical shifts of the carbon atoms of proteinaceous material, of carbohydrates, and of the aliphatic moieties in lignin overlap and thus the assignment is not straightforward. Table 5 gives the most plausible assignments, together with the classes of biological macromolecules. The corresponding data for the nitrogen spectra are contained in Table 6. For

Table 3. Variation of the magnetization transfer time (ms) for the magnetization of the $\mathrm{N}-15$ spins $T_{\mathrm{NH}}$ in various composts, its starting materials and its fractions

\begin{tabular}{lccccc}
\hline Signal (ppm) & $-200 /-220$ & $-220 /-285$ & $-285 /-300$ & $-300 /-325$ & $-325 /-350$ \\
\hline $\begin{array}{l}\text { Starting material: } \\
\text { Wheat }\end{array}$ & - & $0.1 \mathrm{~ms}$ & $0.1 \mathrm{~ms}$ & - & - \\
$\quad$ Lolium & - & $0.2 \mathrm{~ms}$ & $0.1 \mathrm{~ms}$ & - & $0.3 \mathrm{~ms}$ \\
$\begin{array}{l}\text { Composts: } \\
\text { Wheat* }\end{array}$ & $0.1-0.2 \mathrm{~ms}$ & $0.1-0.2 \mathrm{~ms}$ & $0.1 \mathrm{~ms}$ & - & \\
Wheat $\dagger$ & $0.1-0.2 \mathrm{~ms}$ & $0.1-0.2 \mathrm{~ms}$ & $0.1-0.3 \mathrm{~ms}$ & $0.1 \mathrm{~ms}$ & $0.1-0.2 \mathrm{~ms}$ \\
$\quad$ Lolium $\dagger$ & - & $0.1-0.2 \mathrm{~ms}$ & $0.1 \mathrm{~ms}$ & $0.1 \mathrm{~ms}$ & $0.3 \mathrm{~ms}$ \\
$\begin{array}{l}\text { Fractions: } \\
\text { NaOH-extract }\end{array}$ & - & $0.1 \mathrm{~ms}$ & $0.1 \mathrm{~ms}$ & $0.1 \mathrm{~ms}$ & $0.3 \mathrm{~ms}$ \\
Residue & $0.1 \mathrm{~ms}$ & $0.1 \mathrm{~ms}$ & $0.1 \mathrm{~ms}$ & $0.1 \mathrm{~ms}$ & - \\
$\quad$ Fulvic acid & $0.2 \mathrm{~ms}$ & $0.3 \mathrm{~ms}$ & - & - & $0.3 \mathrm{~ms}$ \\
Humic acid & $0.1 \mathrm{~ms}$ & $0.1-0.2 \mathrm{~ms}$ & - & - & $0.3-0.4 \mathrm{~ms}$ \\
\hline
\end{tabular}

* $60 \%$ WHC. + Water saturation.

Table 4. Variation of the proton spin lattice relaxation time in the rotating frame of the $\mathrm{N}-15$ enriched materials $T_{1 \mathrm{H}}$, their composts and some of their fractions

\begin{tabular}{lccccc}
\hline Signal (ppm) & $-200 /-220$ & $-220 /-285$ & $-285 /-300$ & $-300 /-325$ & $-325 /-350$ \\
\hline $\begin{array}{l}\text { Starting material: } \\
\quad \text { Wheat }\end{array}$ & - & $5.7 \mathrm{~ms}$ & - & $2.9 \mathrm{~ms}$ & - \\
$\quad$ Lolium & $5.8 \mathrm{~ms}$ & $5.5 \mathrm{~ms}$ & $5.5 \mathrm{~ms}$ & $6.7 \mathrm{~ms}$ & \\
Composts: & & & & & \\
$\quad$ Wheat* & $3.1-6.6 \mathrm{~ms}$ & $4.0-4.9 \mathrm{~ms}$ & $4.1-5.5 \mathrm{~ms}$ & - & $6.1-7.1 \mathrm{~ms}$ \\
$\quad$ Wheat $\dagger$ & $5.0-5.9 \mathrm{~ms}$ & $3.5-5.6 \mathrm{~ms}$ & $3.0-5.0 \mathrm{~ms}$ & $3.3-3.6 \mathrm{~ms}$ & $3.0-7.0 \mathrm{~ms}$ \\
$\quad$ Lolium $\dagger$ & - & $5.3-6.2 \mathrm{~ms}$ & $4.0-5.1 \mathrm{~ms}$ & $3.6 \mathrm{~ms}$ & $3.0 \mathrm{~ms}$ \\
Fractions: & - & $4.2 \mathrm{~ms}$ & $4.2 \mathrm{~ms}$ & $3.6 \mathrm{~m}$ & $6.1 \mathrm{~ms}$ \\
$\quad$ NaOH-extract & - & $4.8 \mathrm{~ms}$ & $3.3 \mathrm{~ms}$ & $3.5 \mathrm{~ms}$ & - \\
$\quad$ Residue & $5.9 \mathrm{~ms}$ & $-2 \mathrm{~ms}$ & - & - & $5.6 \mathrm{~ms}$ \\
$\quad$ Fulvic acid & $4.8 \mathrm{~ms}$ & $3.4 \mathrm{~ms}$ & - & - & $2.5-4.1 \mathrm{~ms}$ \\
$\quad$ Humic acid & $5.7 \mathrm{~ms}$ & & & & \\
\hline
\end{tabular}

* $60 \%$ WHC. + Water saturation. 
Table 5. Possible assignments for the C-13 NMR spectra

\begin{tabular}{|c|c|}
\hline $\begin{array}{l}\text { Chemical shift } \\
\text { range (ppm) }\end{array}$ & Assignment \\
\hline $220-160$ & Carboxyl/carbonyl groups \\
\hline $160-140$ & Aromatic COR or CNR groups \\
\hline $140-120$ & Aromatic C-H carbons \\
\hline $120-110$ & Aromatic $\mathrm{C}-\mathrm{H}$ carbons in guajacyl $\mathrm{C}-2, \mathrm{C}-6$ \\
\hline $110-90$ & $\begin{array}{l}\text { Carbohydrate derived structures, anomeric carbon of carbohydrates, } \\
\text { C-2, C-6 of syringyl units }\end{array}$ \\
\hline $90-60$ & $\begin{array}{l}\text { Carbohydrate derived structures ( } \mathrm{C}-2 \text { to } \mathrm{C}-5) \text { in hexoses, } \\
\mathrm{C} \text { - of some amino acids, higher alcohols, aliphatic part of lignin structures }\end{array}$ \\
\hline $60-45$ & Methoxyl groups and C-6 of some polysaccharides C- of some amino acids, \\
\hline $45-25$ & Methylene groups in aliphatic rings and chains (lipids or proteins) \\
\hline $25-0$ & Methyl groups bound to carbon \\
\hline
\end{tabular}

Table 6. Possible assignments for the N-15 NMR spectra

\begin{tabular}{|c|c|}
\hline $\begin{array}{l}\text { Chemical shift } \\
\text { range (ppm) }\end{array}$ & Assignment \\
\hline $\begin{array}{l}-145 \text { to }-220 \\
-220 \text { to }-285 \\
-285 \text { to }-300 \\
-300 \text { to }-325 \\
-325 \text { to }-375\end{array}$ & $\begin{array}{l}\text { Indole, imidazole, uric acid, purine/pyrimidine. pyrrole } \\
\text { Amide/peptide. lactame (pyrrole) } \\
\mathrm{NH} \text { in guanidine } \\
\mathrm{NH}_{2-} \text { and } \mathrm{NR}_{2-\text { groups }} \\
\mathrm{NH}_{3}^{+} \text {and } \mathrm{NR}_{3}^{+} \text {-groups, } \mathrm{NH}_{4}^{+}\end{array}$ \\
\hline $\begin{array}{l}\text { Missing signals: } \\
25 \text { to }-25 \mathrm{ppm} \\
-25 \text { to }-90 \mathrm{ppm} \\
-90 \text { to }-145 \mathrm{ppm}\end{array}$ & $\begin{array}{l}\text { Nitrate, nitrite, nitro groups* } \\
\text { Imine, phenazine, pyridine } \\
\text { purine (N-7), nitrile groups }\end{array}$ \\
\hline
\end{tabular}

this nucleus the assignments are less ambiguous, since the groups of signals are well separated in most spectra. The difficulty is in the definition of the low field shoulder of the main peak between -220 and $-145 \mathrm{ppm}$. From the existing data it cannot be decided whether this peak results only from a fraction of amide/peptide nitrogen with a very short spin spin relaxation time, or derives from heterocyclic aromatic nitrogen-containing ring structures.

\section{Quantitative analysis of the spectra}

When the first C-13 NMR spectra of humic materials in aqueous solution were measured, the techniques available did not permit a thorough analysis of the relaxation rates and thus the quantitative analysis was limited (González-Vila et al., 1976). The introduction of C-13 CPMAS into this field of research (Wilson, 1987) also started with spectra that could be analysed only qualitatively.

Based on the discussion of instrumental parameters employed in this study, partial integrals of solution $\mathrm{N}-15$ and $\mathrm{C}-13$ spectra can be quantitatively correlated with the relative concentration of the nuclei in the defined ranges of chemical shifts. For CPMAS NMR this is less clear. However, extensive comparisons of
C-13 solution NMR and C-13 CPMAS spectra have shown, that for most humic materials (Fründ and Lüdemann, 1989a,b,1991), the partial integrals of both types of spectra are identical within the limits of experimental error. This comparison was also carried out for the N-15 spectra given below, and for this nucleus quantitative agreement was also found (see Table 7).

\section{Chemical characterization of the spectra}

Two series of spectra are presented in Fig. 5 from the long term composting experiment with green wheat stems. The most pronounced changes are seen in the C-13 spectra, where the central region of chemical shifts between 45 and $110 \mathrm{ppm}$ exhibits the greatest losses in intensity compared to all other ranges; this is a general phenomenon in decomposing studies, also observed by Inbar et al., (1989). Relative increases in intensity are most apparent for the carboxyl/carbonyl range of chemical shifts $(160-220 \mathrm{ppm})$ and for the aromatic region (110-160 ppm). In Fig. 6, the relative intensities are graphically presented for the four integration ranges characterized in Table 5. A more realistic characterization of the composting processes can be discerned from Fig. 7 , where the relative

Table 7. Comparison of the relative intensities observed in $\mathrm{N}-15$ solution and CPMAS spectra of the sodium hydroxide extract from a $L$. perenne compost (100\% WHC)

\begin{tabular}{|c|c|c|c|c|c|c|c|c|c|c|}
\hline \multirow[b]{2}{*}{ Signal (ppm) } & \multicolumn{2}{|c|}{$-145 /-220$} & \multicolumn{2}{|c|}{$-220 /-285$} & \multicolumn{2}{|c|}{$-285 /-300$} & \multicolumn{2}{|c|}{$-300-325$} & \multicolumn{2}{|c|}{$-325 /-375$} \\
\hline & $\mathrm{S}^{*}$ & $\mathrm{~L} \uparrow$ & $S$ & L & $S$ & L & $S$ & $\mathbf{L}$ & $S$ & $\mathrm{~L}$ \\
\hline 7 days & 1.6 & 0.9 & 86.5 & 88.0 & 3.3 & 1.7 & 3.5 & 2.2 & 5.1 & 7.2 \\
\hline 174 days & 2.7 & 1.7 & 86.9 & 85.5 & 3.3 & 3.0 & 2.9 & 3.4 & 4.2 & 6.4 \\
\hline 248 days & 1.8 & 1.8 & 86.0 & 85.4 & 3.7 & 1.9 & 4.9 & 6.9 & 3.6 & 4.0 \\
\hline
\end{tabular}

\footnotetext{
* Solid state. $\uparrow$ Liquid.
} 
green wheat

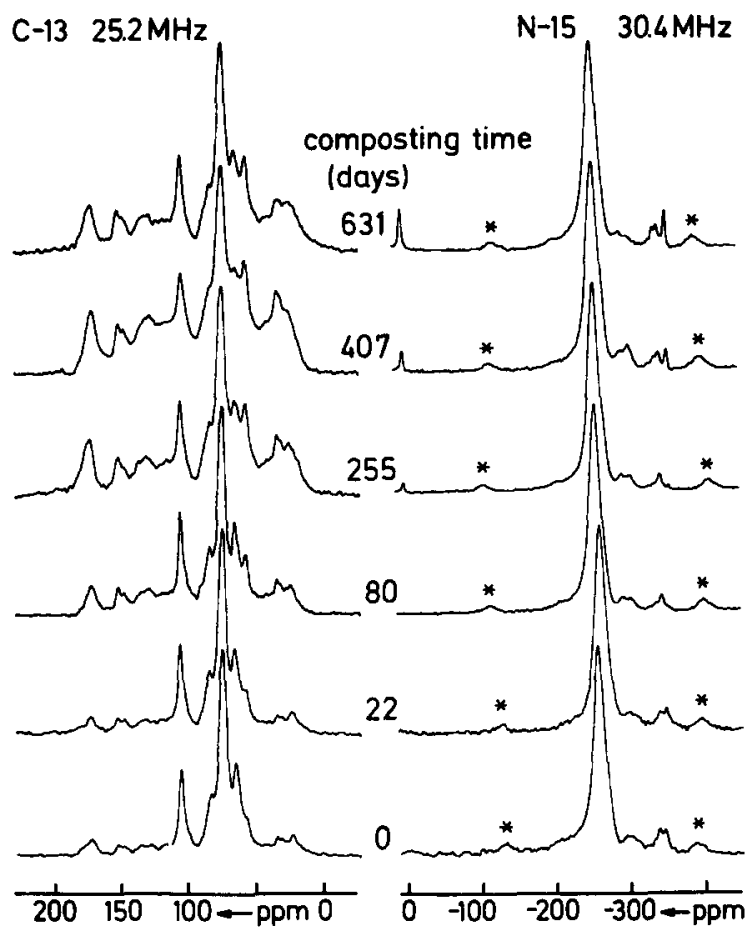

Fig. 5. C-13 and N-15 CPMAS spectra of composted N-15 enriched green wheat stems as a function of the composting period $\left(60 \%\right.$ WHC). ${ }^{*}$ Spinning side bands

intensities are reported on an absolute basis, considering the total carbon loss of the samples. From these curves it is apparent that all ranges of chemical shift lose intensity, although the initial loss rate is

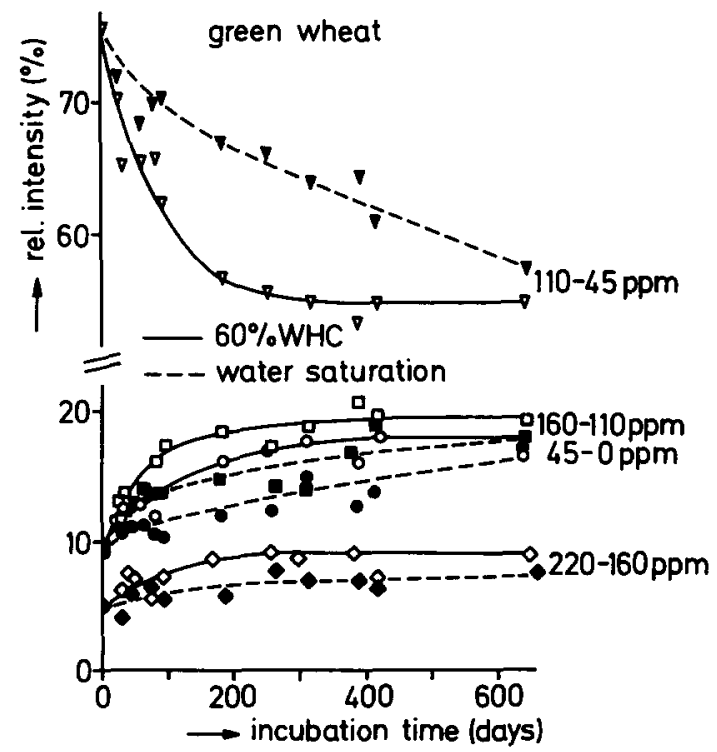

Fig. 6. Relative Intensities in the C-13 CPMAS spectra as a function of composting period for $\mathrm{N}-15$ enriched green wheat material of the four ranges of chemical shift specified in Table 5 .
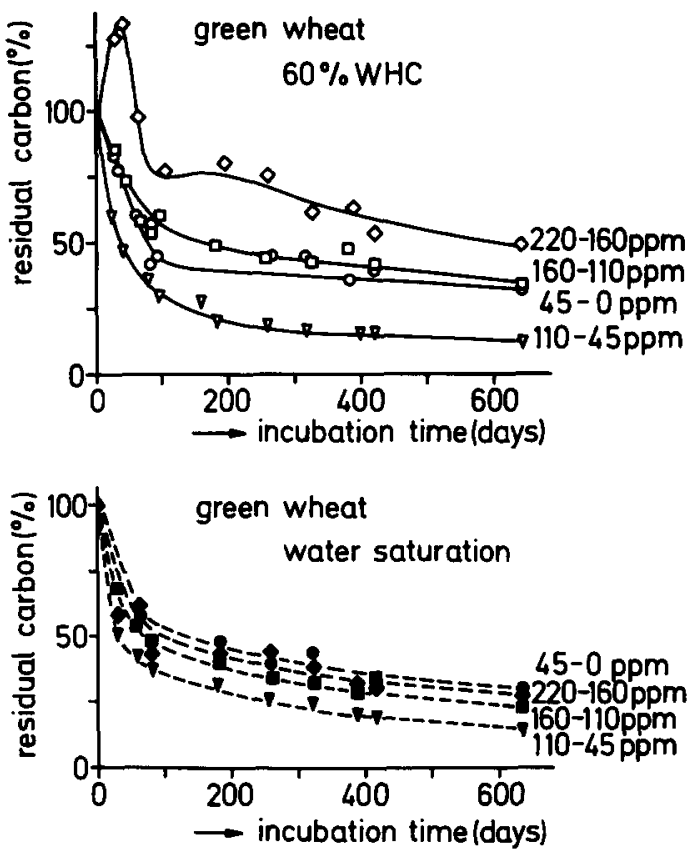

Fig. 7. Relative carbon loss in the four ranges of chemical shift as obtained from a combination of the data given in Figs 2 and 6 . (The concentration in the starting material has been set for all four ranges to $100 \%$.)

largest for the range between 45 and $110 \mathrm{ppm}$. After approx. 100 days, all loss rates become fairly similar. The obvious interpretation of this result is that in the first phase of composting the carbohydrates are utilized preferentially. A similar phenomenon has been observed in naturally-degraded plant matter in peats (Hammond et al., 1985), forest soils and degraded wood (Hatcher et al., 1982; Hedges et al., 1985). It is also clear, however, that decomposition starts elsewhere, with the exception of the carboxyl/carbonyl region. Here, at least at $60 \% \mathrm{WHC}$, an initial increase in concentration can be seen, which indicates either the formation of more carboxyl groups in the lignin or carbohydrate moieties or the formation of more amino acids from microbially digested starting material. As is already apparent from the gross rate of decomposition, as given by the carbon- and weight-loss in Fig. 2, the overall rates decrease with incubation time. Figures 6 and 7 similarly show that this is also the case for all four fractions of carbon, as defined by the chemical shift ranges.

The N-15 spectra of Fig. 5 do not change much with time. They consist, for all composts studied, of a very intense signal between -220 and $-285 \mathrm{ppm}$ that under all conditions accounts for more than $80 \%$ of the total intensity. On the high field side, in the -300 to $-325 \mathrm{ppm}$ range, two weak peaks are clearly resolved that must be ascribed to amino groups and alkylated amino groups. The absorptions between -325 and $-375 \mathrm{ppm}$ can be assigned to amino groups $-\mathrm{NH}_{3}^{+},-\mathrm{NR}_{3}^{+}$, and ammonium ions $\mathbf{N H}_{4}^{+}$. In Fig. 8, the relative intensities are given as a function 


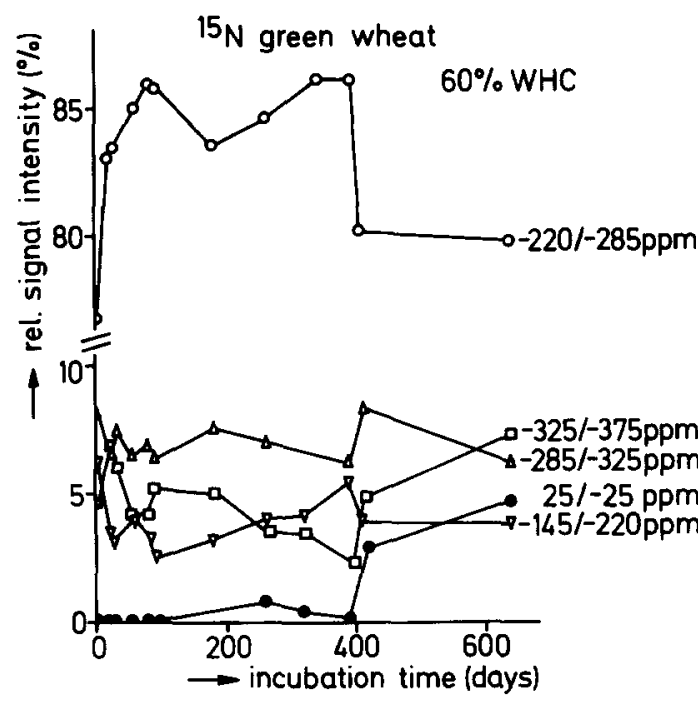

Fig. 8. Relative signal intensities of the series of $\mathrm{N}-15$ spectra in Fig. 5. Green wheat stems composted at $60 \%$ WHC. These data correspond to a nitrogen loss during composting of approx. $30 \%$.

of composting time. After a composting period of more than 250 days a new signal develops around 0 ppm in the N-15 spectra of Fig. 5 that increases in intensity during the remaining period studied and can be assigned to nitrate ions. The sharp decrease in the intensity of the main amide peak results from mineralization, and the formation of nitrate ions, formed by nitrification of ammonia. Additional free ammonia appears after approx. 400 days as indicated by a sharp signal at $-358 \mathrm{ppm}$.

Test experiments showed that the signals at $-358 \mathrm{ppm}$ and $0 \mathrm{ppm}$ have considerably longer magnetization transfer times than the rest of the intensities observed. This corroborates our assignments, since a higher molecular mobility tends to increase $T_{\mathrm{NH}}$ (Fyfe, 1983). Thus in these spectra, the intensity of $\mathrm{NO}_{3}^{-}$and $\mathrm{NH}_{4}^{+}$is underestimated, since they were obtained with the standard pulse protocol. The appearance of the nitrate ion is also remarkable for another reason. It can be argued that nitrogencontaining heterocycles in SOM are not detected by the N-15 CPMAS techniques, since they do not have directly attached protons and thus cannot relax via dipole-dipole interaction with protons. This certainly also holds true for nitrate ions. A comparison of the molecular dimensions of nitrate ions and nitrogen containing moieties in heterocycles shows that the distance of closest approach for protons from neighboring molecules, or other parts of the same molecule, is certainly very similar for both structures. Yet, signals definitely assignable to heterocycles or Schiff bases are lacking (compare Table 6). The only chemical shift region in the N-15 spectra where heteroaromatics could be hidden is the broad unresolved foot on the low field side of the main amide/peptide peak between -145 to $-220 \mathrm{ppm}$. In our opinion, this intensity is most likely caused by some nitrogen of indole and imidazole structures such as histidine or tryptophane. Integration of this region, however, indicates that even if all intensity in this range results from the heterocyclic structures identified in Table 6 , they contribute less than $5 \%$ to the total nitrogen in all composts.

The composting of $90 \% \mathrm{~N}-15$ enriched $L$. perenne grass is described by the series of spectra presented in Fig. 9. There are significant quantitative differences between the two series of C-13 spectra in Fig. 5 and Fig. 9, even though the qualitative trends are very similar. The largest carbon loss occurs in the chemical

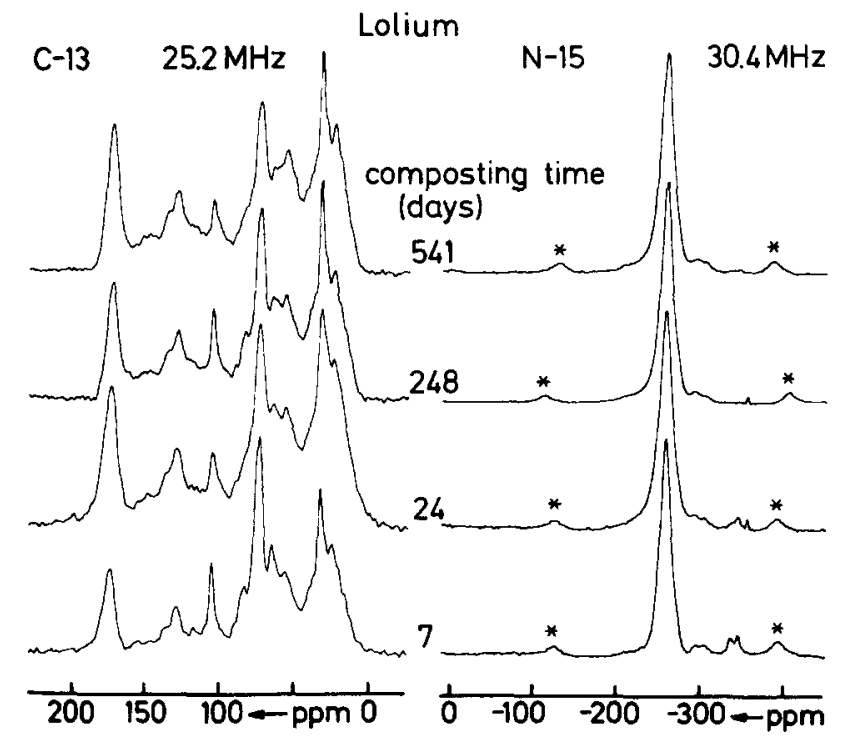

Fig. 9. C-13 and N-15 CPMAS spectra from $L$. perenne grass composts produced at $60 \%$ WHC. The starting material was $90 \%$ enriched with N-15. *Spinning side bands. 

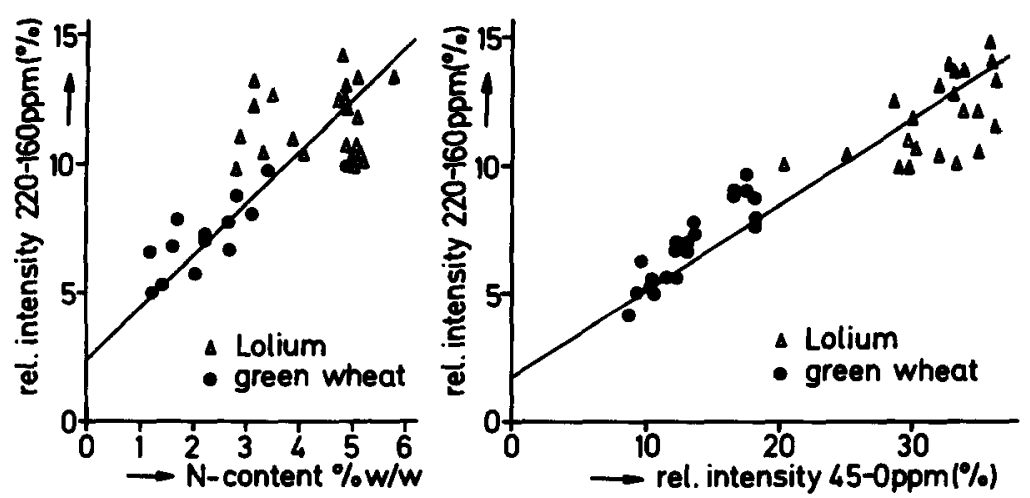

Fig. 10. Correlation diagram between the total nitrogen content of the probe and the intensity in the carboxyl/amide range (160-220 ppm) of C-13 chemical shift. (A) The line drawn through the experimental points is given by $y=2.0 x+2.4 \mathrm{SD}: 0.184$. (B) Correlation between the $\mathrm{C}-13$ signal intensities in the aliphatic range of chemical shift $(45-0 \mathrm{ppm})$ and the carboxyl/amide range $(160-220 \mathrm{ppm}) . y=0.37 x+4.5$

SD: 0.138 .

shift range between 110 and $45 \mathrm{ppm}$. In all other ranges an apparent increase is seen. The rye grass has a much higher nitrogen content than the green wheat stems. The aliphatic carbon, the carboxyl groups, and the aromatic region are more intense in this starting material. The overall pattern of composting is, however, very similar to the first example given. Again after a period of approx. 100 days, no significant changes in the relative concentration are seen between the four chemical shift ranges. The high intensity in the aliphatic range, apparent in Fig. 9, has sometimes been ascribed to the relative enrichment of long chain lipids and dicarboxylic acids (Hatcher et al., 1985; Almendros et al., 1991). An alternative explanation, however, is suggested by the data collected in these four series of composting experiments. In Fig. 10, the total nitrogen content is plotted against the intensity in the carboxyl/carbonyl/amide region of chemical shifts (160-220 ppm). Obviously there exists a positive correlation between these two parameters, indicating that a significant part of this signal range may be attributable to amide groups, which are not separable in the $\mathrm{C}-13$ spectra from carboxylic groups. The correlation between the chemical shift range 160$220 \mathrm{ppm}$ and the aliphatic region $0-45 \mathrm{ppm}$ is also positive. More important, however, is the slope of this correlation. Obviously the intensity in the aliphatic range increases only twice as fast as in the carboxyl region. Taken together, these two correlations are best explained by the assumption that a significant part of the aliphatic region results from the rather short side chains of amino acids in proteins and proteinaceous material, and not from long chain mono- or, dicarboxylic acids. Changes in the relative intensities in the $\mathrm{N}-15$ spectrum of the rye grass compost follow much the same pattern as observed for the green wheat stems. These data are compiled in Fig. 11. The differences in the relative intensities of the free amino and ammonium nitrogens with increasing incubation time of the Lolium and the wheat samples can be explained by nitrification, denitrification and ammon- ification processes. These processes are dependent upon the sample material and incubation conditions. Therefore different behavior of different sample material is expected.

To determine whether more resolution and thus more information could be gathered from the spectra of the fractionation products of the freeze dried standard sodium hydroxide extracts, several composts were extracted in this way. Some of the corresponding spectra are given in Fig. 12. In the early composting period the C-13 CPMAS NMR spectra of the residue and the extract are different. This may be attributed to proteinaceous material and lignins which are being enriched in the soluble fraction, whereas the residues contain signals predominantly from carbohydrates. However, after longer periods the two spectra become more similar and both fractions show almost identical intensity distributions. This is very similar to the situation observed for many soils (Wilson, 1987; Krosshavn et al., 1992), where the aqueous sodium hydroxide extract gives fairly similar spectra in comparison to the whole soil. This is a clear indication

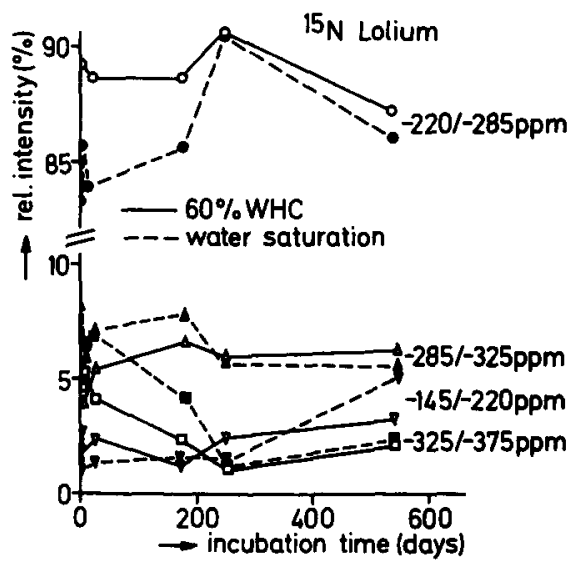

Fig. 11. Relative intensities of the $N-15$ signals of the $L$. perenne composts as a function of composting period. 


\section{Lolium C-13}

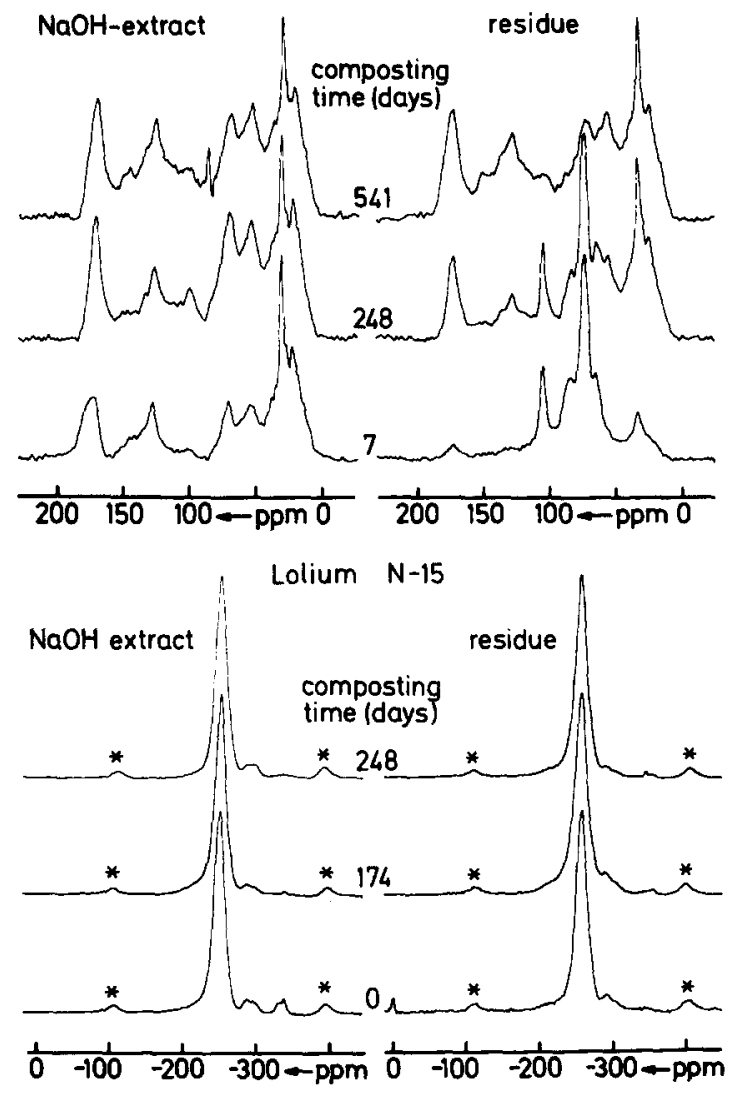

Fig. 12. C-13 and N-15 CPMAS spectra of the sodium hydroxide extract and the residue of the $L$. perenne composts at various periods of composting. *Spinning side bands.

that the standard fractionation with aqueous $\mathrm{NaOH}$ does not separate the SOM into fundamentally different fractions, but rather that minor differences in solubility determine which of the macromolecules are dissolved and which remain in the residue. The N-15 spectra also reveal only minor differences in the small upfield signals and in the foot of the peptide/amide line.

In Fig. 13, the N-15 CPMAS spectra of all fractionation products of a $\mathrm{N}-15$ enriched $L$. perenne compost are given. The most pronounced difference seen in this series is that the two most soluble fractions contain a significantly higher amount of free amino groups than the rest. The poor signal to noise ratio of the washings results only from the very small sample size that we were able to collect. In the wet chemical analysis, the differentiation between the amino acid/proteinaceous fraction of the nitrogen in SOM and the claimed heterocyclic compounds is done by acid hydrolysis in boiling aqueous $6 \mathrm{~N} \mathrm{HCl}$. The rationalization is that all amide/peptide bonds are hydrolyzed during this process (Greenfield, 1972; Schnitzer, 1985), although Greenfield (1972) observed that not all peptide bonds are hydrolyzed under these acidic conditions if carbohydrates and their decompo- sition products are present in the SOM. Figure 14 contains the N-15 CPMAS spectra collected from a green wheat compost before and after hydrolysis. The intensities in the two main spectra can only be compared qualitatively, they permit no conclusion about the absolute amounts of nitrogen in the two samples. It is clear from the vertically expanded spectrum of the residue (inset in Fig. 14) that all intensities in this spectrum result from amide/peptide structures and amino-groups. The sample studied here certainly does not contain a significant concentration of heterocyclic nitrogen structures.

Another attempt to check the results obtained by the solid state technique is presented in Fig. 15. Here solution spectra of the sodium hydroxide extracts from the oldest $L$. perenne composts (541 days of incubation) are shown. For comparison, the spectra of a fulvic and a humic acid prepared after 174 days of incubation are included. None of the four spectra suggest the presence of heterocyclic N-15 containing moieties. The sodium hydroxide extracts were prepared from material that had lost about $80 \%$ of its total carbon and nitrogen content during the 541 days of incubation, yet it still shows no indication of any chemical transformation of the nitrogencontaining peptide/amide structures into heterocyclic compounds.

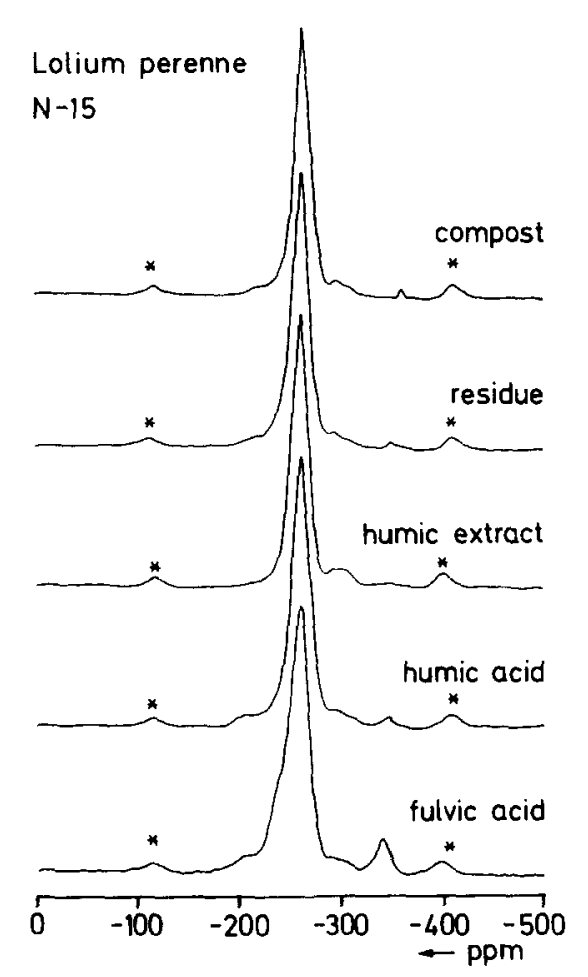

Fig. 13. N-15 CPMAS spectra of the fractions as obtained from the standard aqueous sodium hydroxide extraction procedure from a $L$. perenne compost after 174 days of incubation at water saturation $(100 \%$ WHC) . *Spinning side bands. 


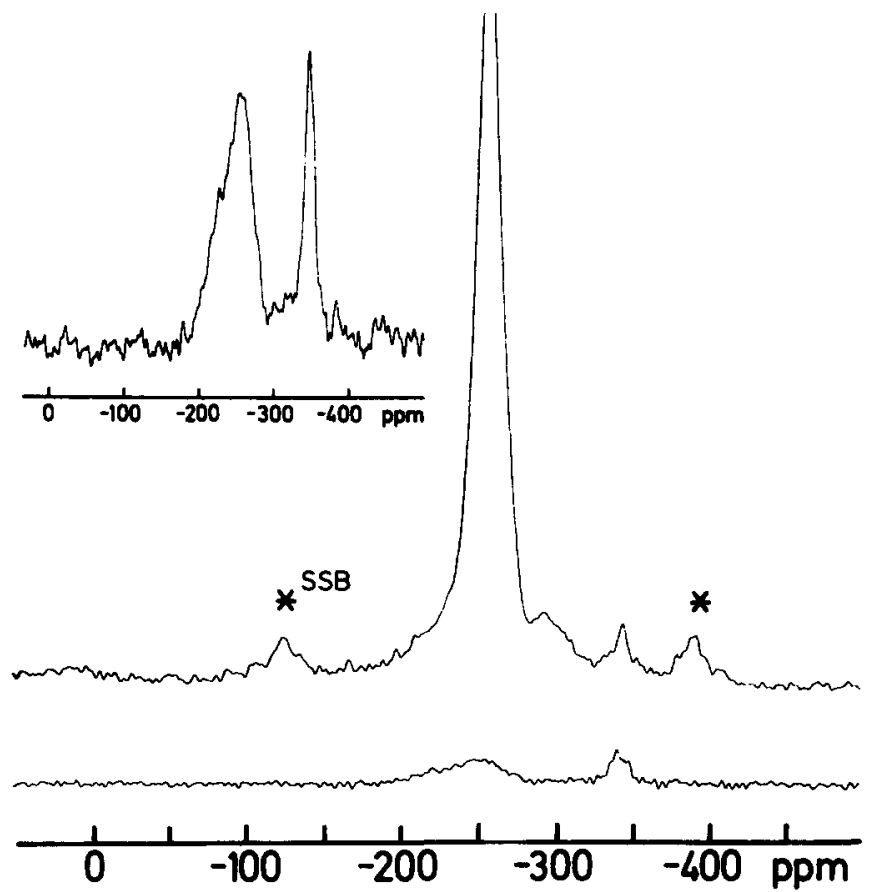

Fig. 14. N-15 CPMAS spectra from a green wheat compost after 30 days of incubation at $60 \%$ WHC before and after hydrolysis with $6 \mathrm{~N}$ aqueous $\mathrm{HCl}$. Inset: vertically expanded spectrum of the residue. *Spinning side bands.

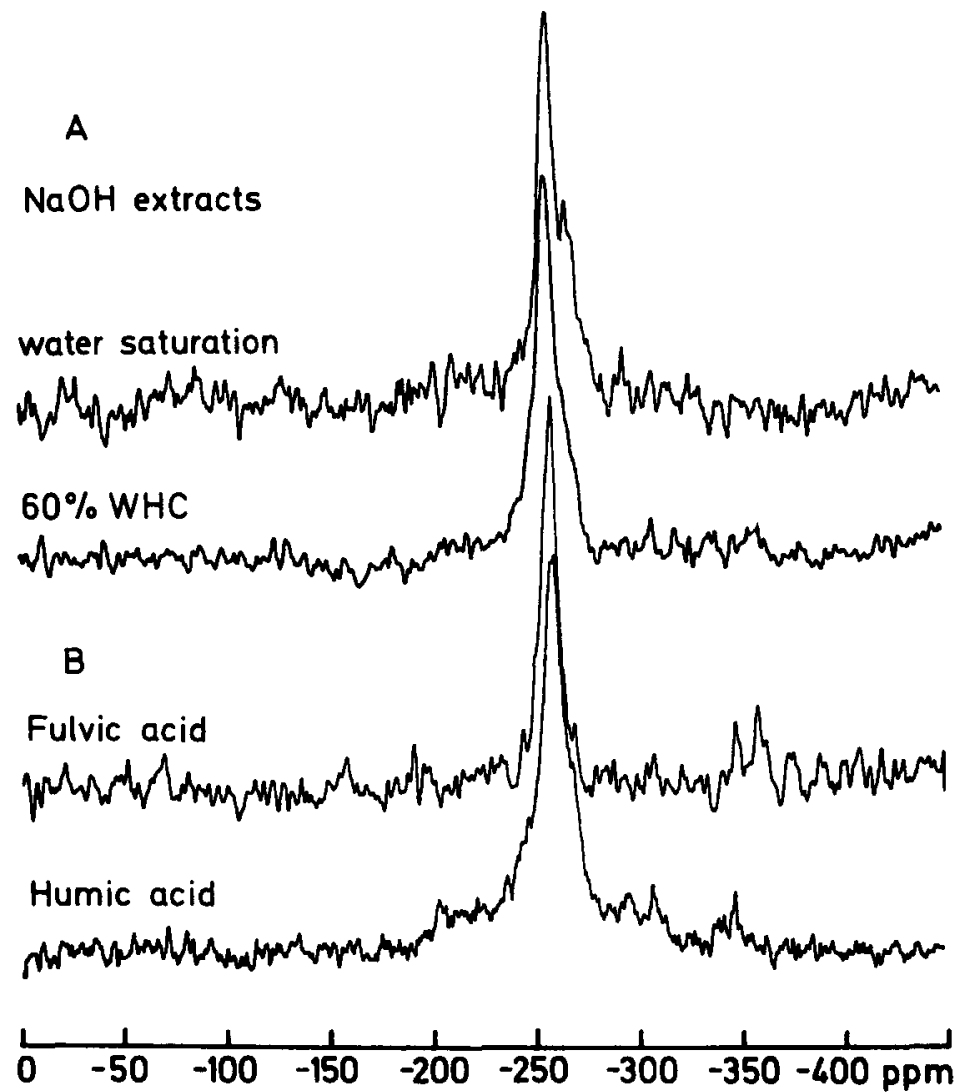

Fig. 15. N-15 solution HR NMR inverse gated decoupled spectra of: (A) two sodium hydroxide extracts obtained from $L$. perenne composts after 541 days of incubation. (B) A standard fulvic and humic acid prepared from a $L$. perenne compost after 174 days of incubation. Solvent: $0.05 \mathrm{~N} \mathrm{NaOH}$ in $\mathrm{H}_{2} \mathrm{O}$. RF frequency: $30.4 \mathrm{MHz}$; pulse delay: $15 \mathrm{~s}$. 


\section{CONCLUDING REMARKS}

These studies on the $\mathrm{N}-15$ enriched plant material provide information about the chemical transformations observed during prolonged composting, and provide conclusions with regard to organic matter degradation in natural and artificial systems. They show that all classes of chemical compounds (lignin/carbohydrates/proteinaceous material) are decomposed during the early days of humification. Taken together with the fact that the overall form, and most details of the spectra remain unchanged with composting, this indicates that the decomposition rates of the individual fractions are influenced more by the physical structure, (i.e. compactness of the molecular packing, accessibility for microorganisms and their extracellular enzymes) than by larger differences in chemical structure. Early, carbohydrates seem to be removed preferentially, similar to observations in natural sedimentary systems. After an initial period of approx. 100 days, all fractions of the remaining material are decomposed at comparable rates. The $\mathrm{C}-13$ and the $\mathrm{N}-15$ spectra give no indication of the synthesis of new chemical structures not found in the starting material: the $\mathrm{N}-15$ spectra remain remarkably uniform during the whole period. The most straightforward explanation of this result is that the major pathway of nitrogen metabolism in these composts involves the breakdown of the proteinaceous plant material and a de novo synthesis of bacterial and fungal proteins and biological nitrogencontaining structures. Under our conditions, the postulated formation of nitrogen-containing heterocycles (Flaig et al., 1975; Stevenson and Kelley, 1985; Schulten et al., 1992) can, at most, play a very minor role. With the experimental experience gathered here, a small series of natural $\mathrm{N}-15$ abundance SOM in the top layer of typical German soils could be studied by N-15 CPMAS (Knicker et al., 1993), albeit with a rather modest resolution and signal to noise ratio. Also these studies do not reveal any N-15 signals that can be ascribed unequivocally to heterocycles.

Acknowledgements--Financial support was obtained from the Federal Department of Science and Technology (Grant Nr. BEO/10339137 C). The technical help by Mr E. Treml and the workshops of our faculty are gratefully acknowledged. This publication owes a great deal to Professor Dr K. Haider, who offered not only invaluable scientific and technical advice, but also donated some of the nitrogen- 15 enriched wheat stems for our composting experiments.

\section{REFERENCES}

Aiken G. R., McKnight D. M., Wershaw R. L. and MacCarthy P. (1985) An introduction to humic substances in soil, sediment and water. In Humic Substances in Soil, Sediment and Water (Edited by Aiken G. R., McKnight D. M., Wershaw R. L and MacCarthy P.), pp. 1-13. Wiley, New York.

Almendros G., Sanz J., González-Vila F. J. and Martin F. (1991) Evidence for a polyalkyl nature of soil humin. Naturwissenschaften 78, 359-362.

Anderson H. A., Bick W., Hepburn A. and Stewart M. (1989)
Nitrogen in humic substances. In Humic Substances II (Edited by Hayes. M. H. B., MacCarthy P., Malcolm R. L. and Swift R. S.), pp. 223-253. Wiley, Chichester.

Benzing-Purdie L. M., Ripmeester J. A. and Preston C. M. (1983) Elucidation of the nitrogen forms in melanoidins and humic acids by nitrogen-15 cross polarization-magic angle spinning nuclear magnetic resonance spectroscopy. J. Agric. Food Chem. 31, 913-915.

Benzing-Purdie L. M., Cheshire M. V., Williams B. L., Sparling G. P., Ratcliffe C. I. and Ripmeester J. A. (1986) Fate of ${ }^{15} \mathrm{~N}$-glycine in peat as determined by ${ }^{13} \mathrm{C}$ and ${ }^{15} \mathrm{~N}$ CPMAS NMR spectroscopy. J. Agric. Food Chem. 34, $170-176$.

Benzing-Purdie L. M., Cheshire M. V. and Williams B. L. (1992) Interactions between peat and sodium acetate, ammonium sulfate, urea or wheat straw, during incubation studied by ${ }^{13} \mathrm{C}$ and ${ }^{15} \mathrm{~N}$ NMR spectroscopy. J. Soil Sci. 43, 113-125

Cheshire M. V., Williams B. L., Spariing G. P., Ratcliffe C. I. and Ripmeester J. A. (1990) Use of ${ }^{15} \mathrm{~N}-\mathrm{NMR}$ spectroscopy to study transformation of nitrogenous substances during incubation of peat. Soil Use and Management 6, 90-92.

Clore G. M., Szabo A., Kay L. E., Driscoll P. C. and Gronenborn A. M. (1990) Deviations from the simple two-parameter model-free approach to the interpretation of nitrogen-15 nuclear magnet relaxation of proteins. $J$. Am. Chem. Soc. 112, $4989-4991$.

Dev S. B., Burum D. P. and Rha C. K.. (1987) High resolution CPMAS and solution NMR studies of polysaccharides. part 1: Starch. Spectrosc. Lett. 20, 853-869.

Flaig W. J. A., Beutelspacher H. and Rietz E. (1975) Chemical composition and physical properties of humic substances. In Soil Compounds 1 (Edited by Gieseking J.E.), pp. 1-211. Springer, New York.

Foster J. C., Zech W. and Würdinger E. (1993) Comparison of chemical and microbiological methods for the characterization of the maturity of composts from contrasting sources. Biol. Fert. Soils 16, 93-99.

Fründ R. (1988) Quantitative Charakterisierung von organischen Bodeninhaltsstoffen mit Hilfe der ${ }^{13} \mathrm{C}$-NMRSpektroskopie. Dissertation, Regensburg.

Fründ R. and Lüdemann H.-D. (1989a) "C-NMR spectroscopy of lignins and lignocellulosic materials. In Physico-Chemical Characterization of Plant Residues for Industrial and Feed Use (Edited by Chesson A. and Ørskov E. R.), pp. 110-117. Elsevier Applied Science, Brüssels.

Fründ R. and Lüdemann H.-D. (1989b) The quantitative analysis of solution and CPMAS-C-13 NMR spectra of humic material. Sci. Total. Environ. 81/82, 157-168.

Fründ R. and Lüdemann H.-D. (1991) Quantitative characterization of soil organic matter and its fractionation products by solid state high resolution $\mathrm{C}-13$ (CPMAS) Spectroscopy. Z. Naturforsch. 46c, 982-988.

Fyfe C. A. F. (1983) Solid State NMR for Chemists. CFC Press, Ontario.

Gerothanassis J. P. (1986) Simple reference baseline subtraction $-90^{\circ}$ pulse sequence for acoustic ringing elimination in pulse fourier transform NMR-spectroscopy. Magn. Res. Chem. 24, 428-433.

González-Vila F. J., Lentz H. and Lüdemann H.-D. (1976) FT-C-13 nuclear magnetic resonance spectra of fungal melanins. Z. Naturforsch. 33c, 291-293.

Greenfield L. G. (1972) The nature of organic nitrogen of soils. Plant Soil 36, 191-198.

Haider K. (1992) Problems related to the humification processes in soils of temperate climate. In Soil Biochemistry Vol. 7 (Edited by Bollag J.-M. and Stotzky G.), pp. 55-94. Marcel Dekker, New York.

Hammond T. E., Cory D. G. Ritchey W. M. and Morita H. (1985) High resolution solide state ${ }^{13} \mathrm{C} n$. m. r. of Canadian peats. Fuel 64, 1687-1695 
Hatcher P. G., Breger I. A., Szeverenyi N. M. and Maciel G. E. (1982) Nuclear magnetic resonance studies of ancient buried wood.-II. Observations on the origin of coal from lignite to bituminous coal. Organic Geochem.4, 9-18.

Hatcher P. G., Breger I. A., Maciel G. E. and Szeverenyi N.M. (1985) Geochemistry of humin. In Humic Substances II (Edited by Hayes M. H. B., MacCarthy P., Malcolm R. L. and Swift R. S.), pp. 275-302. Wiley, Chichester.

Hedges J. I., Cowie G. L., Ertel J. R., Barbour R. J. and Hatcher P.G.(1985) Degradation of carbohydrates and lignins in buried woods. Geochim. Cosmochim. Acta 49 , $701-711$.

Hsieh Y. P. (1992) Pool size and mean age of stable organic carbon in cropland. Soil. Sci. Soc. Am. J. 56, 460-464.

Inbar Y., Chen Y. and Hadar Y. (1989) Solid-state carbon-13 nuclear magnetic resonance and infrared spectroscopy of composted organic matter. Soil Sci. Soc. Am. J. 53, 1695-1701.

Kirchmann H. and Bergqvist R. (1989) Carbon and nitrogen mineralisation of white clover plants (Trifolium repens) of different age during aerobic incubation with soil. $Z$. Pflanzenernähr. Bodenk. 152, 283-288.

Knicker H. (1993) Quantitative ${ }^{15} \mathrm{~N}$ - und ${ }^{13} \mathrm{C}-\mathrm{CPMAS}-F e s-$ tkörper und ${ }^{15} \mathrm{~N}$-Flüssigkeits-NMR-Spektroskopie an Pflanzenkomposten und natürlichen Böden, Dissertation, Universität Regensburg.

Knicker H., Fründ R. and Lüdemann H.-D. (1995) Characterization of nitrogen in plant composts and native humic material by natural abundance N-15 CPMAS and solution spectra. In Nuclear Magnetic Resonance Spectroscopy in Environmental Science and Technology (Edited by Nanny M., Minear R. A. and Leenheer J. A.) Oxford Press, London. In press
Knicker H., Fründ R. and Lüdemann H.-D. (1993) The chemical nature of nitrogen in native soil organic matter. Naturwissenschaften 80(5), 219-221.

Krosshavn M., Kögel-Knabner I., Southon T. and Steinnes E. (1992) The influence of humus fractionation on the chemical compostion of soil organic matter studied by solid-state ${ }^{13} \mathrm{C}$ NMR. J. Soil Sci. 43, 473-483.

Martin G. J., Martin M. L. and Gouesnard J. P. (1981) ${ }^{15} N-N M R$ Spectroscopy. Springer, Berlin.

Preston C. M., Newman R. H. and Rother P. (1994) Effects of cultivation on the organic matter of particle-size fractions in a grassland soil using C-13 CPMAS NMR. J. Soil Sci. 157, 26-35.

Schnitzer M. (1985) Nature of nitrogen of humic substances from soil. In Humic Substances in Soil, Sediment and Water (Edited by Aiken G. R., McKnight D. M., Wershaw R. L and MacCarthy P.), pp. 300-325. Wiley, New York.

Schulten H. R., Plage B. and Schnitzer M. (1992) Structural studies on soil humic acids by Curie-point pyrolysis-gas chromatography/mass spectrometry. Soil Sci. 153, 205 209.

Stevenson F. J. and Kelley K. R. (1985) Stabilization, chemical characteristics and availability of immobilized nitrogen in soils.. In Nitrogen and the Environment (Edited by Malik K. A., Mujtaba Naqvi S. H. and Aleem M. I. H.), pp. 107-123. Ghularni Printers, Lahore.

Wilson M. A. (1987) NMR-Techniques and Application in Geochemistry and Soil Chemistry. Pergamon Press, Oxford.

Witanowski M., Stefaniak L. and Webb G. A. (1986) Nitrogen NMR Spectroscopy. Annual Reports on NMRspectroscopy 18. Academic Press, London. 